\title{
Artigo de Revisão / Review Article \\ Uma revisão sobre a controversa classificação fisionômica da Floresta de Linhares, norte do Espírito Santo
}

\author{
A review on the controversial physiognomic classification of the Linhares Forest, \\ northern Espírito Santo
}

Felipe Zamborlini Saiter ${ }^{1,5}$, Samir Gonçalves Rolim ${ }^{2}$, Salim Jordy Filho ${ }^{3} \&$ Ary Teixeira de Oliveira-Filho ${ }^{4}$

\begin{abstract}
Resumo
Apresentamos uma revisão das visões controversas acerca da classificação fisionômica da Floresta de Linhares, aqui definida como a floresta sobre tabuleiros costeiros que ocorre entre os rios Doce e Barra Seca, no norte do Espírito Santo. Compilamos informações sobre o clima estacional dessa região e analisamos a inter-relação das variações interanuais e da dinâmica sazonal da precipitação com atributos ecológicos da floresta. Nossas interpretações revelaram que dados mensais médios de precipitação não exprimem a realidade dos períodos biologicamente secos ano a ano e suas consequências sobre a fisionomia da vegetação. Percebemos que a Floresta de Linhares pode se manifestar como semidecídua ou perenifólia, a depender da severidade da seca em um dado período. Então, propomos que a flexibilidade do regime de renovação foliar da Floresta de Linhares deve ser considerada em sua classificação. Sugerimos classificar a floresta duplamente como estacional semidecidual nos períodos anuais ou supra-anuais caracterizados por deficit hídrico pronunciado, e como floresta estacional perenifólia nos períodos anuais ou supra-anuais sem deficit hídrico significativo.
\end{abstract}

Palavras-chave: deficit hídrico, floresta de tabuleiro, floresta estacional semidecidual, floresta estacional perenifólia, sazonalidade de precipitação.

\begin{abstract}
We present a review of the controversial points of view concerning the physiognomic classification of Linhares Forest, which is defined here as the forest over coastal tablelands that is found between the Rio Doce and the Rio Barra Seca, in the north of Espírito Santo. We compiled information about the seasonal climate of such region and analyzed the relationship of both the interannual variation and the seasonality of the rainfall with the ecological attributes of the forest. Our interpretations unveiled that the average monthly rainfall does not express the reality of the biologically dry periods year after year nor does it express the consequences on the vegetation physiognomy. We perceived that Linhares Forest may manifest itself as semideciduous or evergreen, depending on the drought severity within a given period. Thus, we propose that the flexibility of Linhares Forest leaf flush regime must be considered in its classification. We suggest a double classification for the forest: one as a seasonal semideciduous forest during annual or supra-annual periods that are characterized by pronounced water deficit and the other as a seasonal evergreen forest during annual or supra-annual periods with no significant water deficit.
\end{abstract}

Key words: water deficit, tableland forest, seasonal semideciduous forest, seasonal evergreen forest, rainfall seasonality.

\footnotetext{
${ }^{1}$ Instituto Federal do Espírito Santo, Rod. ES-080, Km 93, São João de Petrópolis, 29660-000, Santa Teresa, ES, Brasil.

${ }^{2}$ Universidade Federal do Espírito Santo, Lab. Ecologia de Restinga e Mata Atlântica, Rod. BR-101 Norte, Km 60, 29932-540, São Mateus, ES, Brasil.

${ }^{3}$ Vale S.A., Av. Dr. Marco Paulo Simon Jardim 3580, Águas Claras, 34006-270, Nova Lima, MG, Brasil.

${ }^{4}$ Universidade Federal de Minas Gerais, Depto. Botânica, Av. Antônio Carlos 6627, Pampulha, 31270-901, Belo Horizonte, MG, Brasil.

${ }^{5}$ Autor para correspondência: fsaiter@ifes.edu.br
} 


\section{Introdução}

A classificação da vegetação tem sido um importante campo de pesquisa científica e atualmente exerce grande influência na organização do conhecimento biológico, planejamento e execução de programas de pesquisa e conservação, formulação de leis para proteção de habitats ameaçados, monitoramento do uso de recursos naturais e estabelecimento de metas para restauração (Peet \& Roberts 2013). O processo de classificação se inicia com a descrição dos atributos da vegetação, passa pela avaliação desses atributos seguindo um certo conjunto de critérios, e termina no reconhecimento de categorias ou tipos vegetacionais (Oliveira-Filho 2009). Em escalas mais amplas de análise, a classificação da vegetação normalmente se apoia em categorias cujas denominações refletem basicamente as formas de vida dominantes e os tipos fisionômicos, expressando assim variações ambientais de larga escala (Box \& Fujiwara 2013).

Entretanto, classificar a vegetação constitui um trabalho bastante desafiador, pois ela é um componente dinâmico da paisagem que pode ter composição e físionomia variando no espaço e no tempo, sendo fruto do determinismo de gradientes ambientais, da variabilidade temporal do clima, da história ecológica e de eventos casuais (Peet \& Roberts 2013). Essa condição multivariável pode levar a múltiplos caminhos semânticos no reconhecimento dos tipos vegetacionais, e a preferência por um desses caminhos, em detrimento de outro, deve sempre considerar o pragmatismo como linha mestra (Mucina 1997). Por exemplo, em um trabalho especialmente pensado para a América do Sul cisandina, Oliveira-Filho (2009) argumentou sobre as vantagens de se adotar uma classificação flexível da vegetação, assumindo certo grau de liberdade sobre o uso de uma terminologia parcialmente padronizada. O que motivou o autor nessa proposição foi a grande dificuldade de se obter uma classificação de vegetação refinada e realista para um território extenso e ambientalmente heterogêneo tendo como base a rígida terminologia dos sistemas tradicionais de classificação.

De fato, a rigidez desses sistemas tradicionais torna-se um problema quando o necessário exercício de observação e monitoramento de atributos ambientais e biológicos revela padrões que não permitem encaixar uma determinada vegetação em apenas um tipo vegetacional. Esse é o caso da floresta que ocorre sobre os tabuleiros costeiros do norte do Espírito Santo, particularmente aquela encontrada entre os rios Doce e Barra Seca e que aqui denominamos de Floresta de Linhares. A despeito do bom nível de conhecimento sobre sua flora, o qual foi conquistado após quase 40 anos de pesquisas botânicas (Peixoto \& Jesus 2016), a classificação dessa floresta ainda representa um interessante ponto para debate no meio científico (Rolim et al. 2016). Notável é a falta de consenso na literatura sobre qual termo melhor expressaria a fisionomia da Floresta de Linhares, se floresta ombrófila densa, floresta estacional semidecidual ou floresta estacional perenifólia (dentre outros termos já utilizados por diferentes autores). É verdade que alguns estudos já se dedicaram a resolver tal controvérsia, por exemplo Engel (2001), Vicens et al. (2004) e Rolim et al. (2016). Mas é provável que eles não tenham sido plenamente convincentes, uma vez que suas interpretações estiveram subjugadas às amarras terminológicas dos sistemas de classificação.

Apoiados nessa realidade, propomos aqui uma revisão histórica sobre o que vários autores vêm pensando a respeito da classificação fisionômica da Floresta de Linhares e aproveitamos para acrescentar algumas impressões embasadas por dados de diferentes fontes, na expectativa de que elas possam contribuir para uma melhor interpretação do cenário fitofisionômico regional. Começamos reunindo informações sobre o ambiente de tabuleiros na região de Linhares e depois relacionamos as variações interanuais e a dinâmica sazonal da precipitação pluviométrica com atributos ecológicos da floresta. Por fim, nos apoderamos de argumentos que julgamos serem suficientes para a proposição de uma nova e flexível classificação da Floresta de Linhares, a qual desejamos que seja útil na atualização de mapeamentos da vegetação na costa atlântica brasileira.

\section{O ambiente de tabuleiros}

em Linhares

Os tabuleiros costeiros de Linhares correspondem a planícies sedimentares originadas no Plioceno (Formação Barreiras), as quais são entrecortadas por vales amplos e rasos e atingem altitudes entre 20 e $100 \mathrm{~m}$. Nessas planícies predominam solos do tipo Argissolo Amarelo Distrófico com horizonte A moderado e horizonte B textural, porosos, bem drenados, com textura variando de arenosa a média no horizonte A e de média a argilosa no horizonte B (Santos et al. 2004). 
Dados climáticos da estação meteorológica da Reserva Natural Vale para a série histórica 1975-2013 (exceto temperaturas de 2010-2012) disponibilizados por Kierulff et al. (2015) e complementados com dados de temperatura do período de 2010-2012 da estação Sooretama do Instituto Nacional de Pesquisas Espaciais (CPTECINPE; <http://sinda.crn2.inpe.br/PCD/SITE/novo/ site/historico/index.php $>$ ) indicam que o clima local é quente e úmido, com verões chuvosos e invernos secos, sendo classificado como Aw de acordo com o sistema de Köppen (1948). A média das temperaturas mínimas é de $18,7^{\circ} \mathrm{C}$ e a média das máximas é de $29,9^{\circ} \mathrm{C}$. Fevereiro é o mês mais quente, com temperatura máxima média de 32,9 ${ }^{\circ} \mathrm{C}$, e julho o mais frio, com temperatura mínima média de $15,2{ }^{\circ} \mathrm{C}$. A precipitação média anual é de $1214,6 \mathrm{~mm}$, mas os índices têm variado entre 816 e $1747 \mathrm{~mm}$ nas últimas quatro décadas (Fig. 1). Anos menos chuvosos $(\leq 1100 \mathrm{~mm})$ correspondem a aproximadamente $45 \%$ dos registros da série histórica, enquanto anos mais chuvosos $(\geq 1400$ $\mathrm{mm}$ ) somam cerca de $20 \%$. As médias mensais de precipitação variam de $37,5 \mathrm{~mm}$ (junho) a 217,1 $\mathrm{mm}$ (novembro) e cerca de $80 \%$ da precipitação anual está normalmente distribuída entre outubro e abril (Fig. 2). A precipitação acumulada na estação seca (abril/maio-setembro) pode cair para apenas $100-130 \mathrm{~mm}$ em anos com estiagens agravadas pelo fenômeno El Niño-Oscilação Sul (ENOS; por exemplo, 1979, 1987, 1998, 2007 e 2010). O ENOS é conhecido por promover alterações atmosféricas que reduzem a precipitação pluviométrica nas porções norte e leste do sudeste brasileiro no outono e inverno (Tedeschi et al. 2016).

Para os propósitos desse trabalho, utilizamos os dados climáticos citados acima para produzir um diagrama de balanço hídrico sequencial (série histórica 1975-2013; Fig. 3) de acordo com Thornthwaite \& Mather (1955). Para tanto, adotamos a planilha BHseq V6.4 (Rolim et al. 1998) e valores de capacidade máxima de armazenamento de água no solo (CAD), índice térmico e constante $a$ de, respectivamente, 200 $\mathrm{mm}, 135,27$ e 3,17. O balanço hídrico sequencial indicou a ocorrência de excedentes em $70 \%$ dos anos da série histórica, sendo predominantes aqueles registrados entre novembro e março. Excedentes extraordinários foram registrados em janeiro-março/1979 $(459,1 \mathrm{~mm})$, outubro/1981janeiro/1982 (541,5 mm), janeiro/1985 (337,5 $\mathrm{mm})$, novembro/2001-janeiro/2002 (530,2 mm), março-abril/2004 (473,9 mm) e dezembro/2013

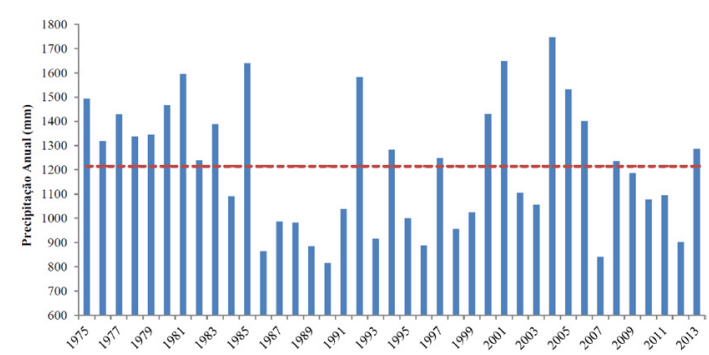

Figura 1 - Precipitação pluviométrica anual na Floresta de Linhares ao longo do período 1975-2013. As precipitações anuais variaram entre 816 e 1747 mm. A precipitação média anual (1214,6 mm) está indicada por uma linha tracejada vermelha.

Figure 1 - Annual rainfall in Linhares Forest over the interval 19752013. Annual rainfall ranged from 816 to $1747 \mathrm{~mm}$. The average annual rainfall $(1214.6 \mathrm{~mm})$ is indicated by a dashed red line.

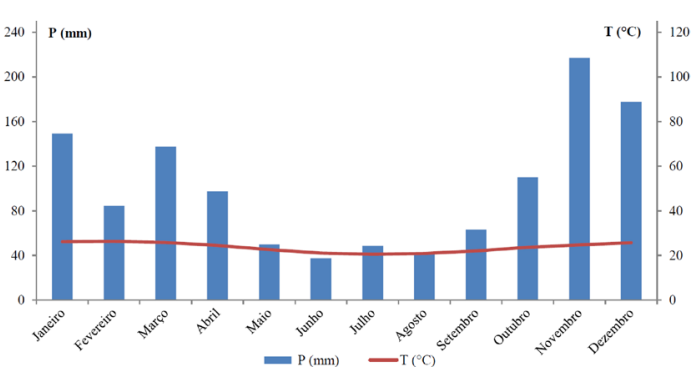

Figura 2 - Diagrama ombrométrico da Floresta de Linhares baseado em dados de temperatura e precipitação pluviométrica (série histórica 1975-2013) da estação meteorológica da Reserva Natural Vale, complementados com dados da estação meteorológica Sooretama do Instituto Nacional de Pesquisas Espaciais. P, precipitação média; T, temperatura média.

Figure 2 - Ombrometric diagram of Linhares Forest based on both temperature data and rainfall data (historical interval 1975-2013) from the weather station of the Reserva Natural Vale, supplemented with data from the weather station Sooretama of the Instituto Nacional de Pesquisas Espaciais. P, average rainfall; T, average temperature.

(232,7 mm). O balanço hídrico sequencial também indicou a ocorrência de deficit hídrico em todos os anos da série histórica. Todavia, a severidade do deficit variou substancialmente de um ano a outro. O menor deficit anual foi registrado em $1978(8,1 \mathrm{~mm})$ e o maior em $2003(496,2 \mathrm{~mm})$. Períodos demasiadamente longos de deficit hídrico (com 8-11 meses contínuos) foram registrados em 1979, 1988, 1990, 1996, 1998, 2002-2003, 2007 e 2012-2013.

O saldo do balanço hídrico foi nitidamente prejudicado quando anomalias climáticas 


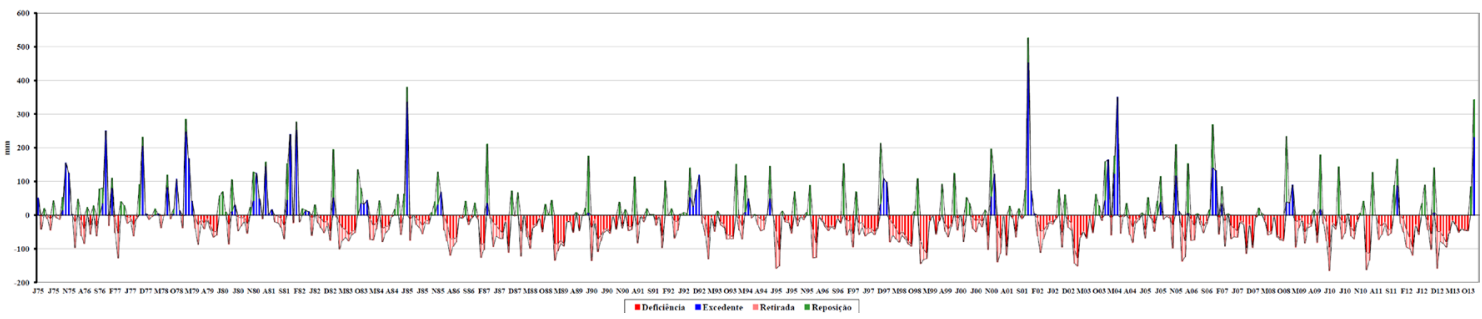

Figura 3 - Balanço hídrico sequencial para a Floresta de Linhares (série histórica 1975-2013) segundo Thornthwaite \& Mather (1955).

Figure 3 - Sequential water balance for Linhares Forest (historical interval 1975-2013), according to Thornthwaite \& Mather (1955).

causadas por bloqueios atmosféricos, os chamados veranicos (para detalhes, ver Cupolillo et al. 2008), derrubaram os totais de precipitação na estação chuvosa, particularmente nos meses de janeiro e fevereiro (observe especialmente o balanço hídrico dos anos de 1987, 1989, 1990, 1995, 1996, 2006 e 2011 na Fig. 3).

\section{A semideciduidade ou a perenidade} da Floresta de Linhares

A Figura 4 retrata as fisionomias da Floresta de Linhares em outubro de 2010 e outubro de 2014, períodos estes considerados como de transição entre estação seca e úmida. Em ambos os casos notamos que a Floresta de Linhares apresentou fisionomias claramente semidecíduas, contrariando alguns dos principais trabalhos sobre a classificação das florestas dessa região (por exemplo, Jordy Filho 1987; IBGE 2004; Engel 2001).

Para compreender a origem dessa controvérsia, faz necessário um resgate histórico sobre a classificação da Floresta de Linhares. Partimos do trabalho pioneiro de Ruschi (1950) sobre a fitogeografia do estado do Espírito Santo, no qual o autor chamou de "mata pluvial dos tabuleiros" ou "floresta perenifólia dos tabuleiros" o conjunto de florestas cobrindo os sedimentos do Terciário (Formação Barreiras) no norte do Espírito Santo. Nesse mesmo trabalho, entretanto, encontramos um mapa fitogeográfico onde duas tipologias de florestas de tabuleiro podem ser identificadas, uma sempre-verde e outra caducifólia (ver reprodução na Fig. 5). Apesar de Ruschi (1950) não destacar em seu texto as características das "florestas dos tabuleiros caducifólias", percebemos que no mapa elas estão distribuídas em áreas mais interioranas, tal como a oeste da Lagoa Juparanã e no trecho inicial da bacia do rio Barra Seca. Por outro lado, as "florestas dos tabuleiros sempre-verdes" ocupam
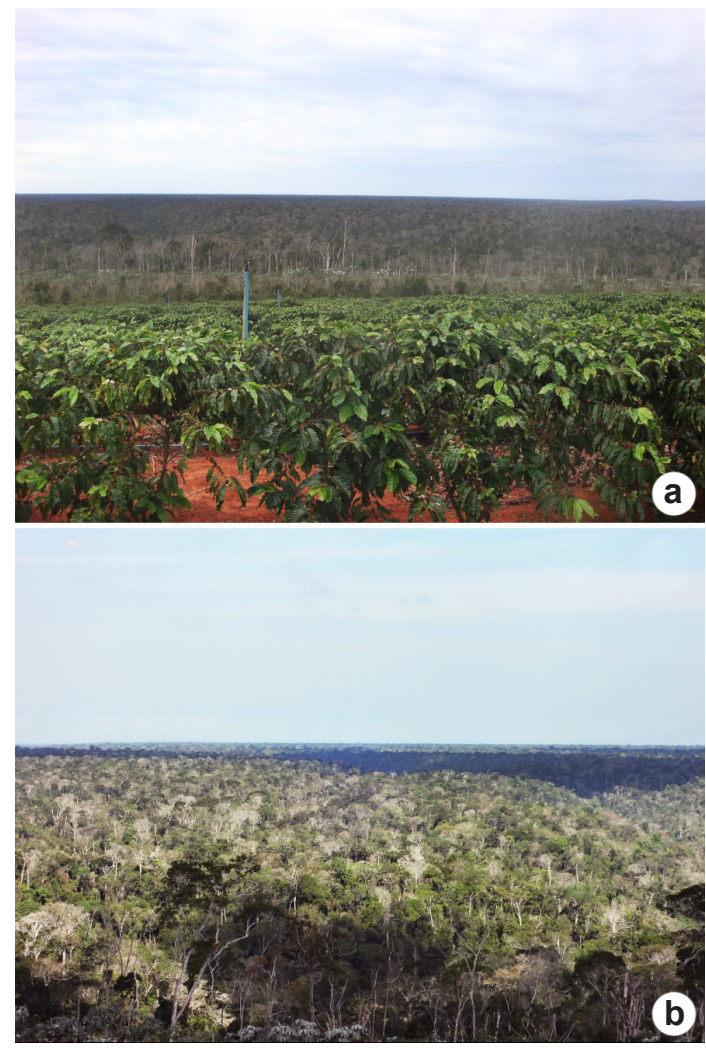

Figura 4 - Fisionomia semidecídua da Floresta de Linhares. Fotografias obtidas no limite oeste da Reserva Biológica de Sooretama - a. (ao fundo) em outubro de 2010; b. em outubro de 2014. O intervalo entre a segunda metade de setembro e o final de novembro é considerado um período de transição seco-úmido. Fotos: a. Gilberto Terra; b. Geovane S. Siqueira.

Figure 4 - Semideciduous physiognomy of Linhares Forest. Pictures taken in the western boundaries of the Reserva Biológica de Sooretama - a. (background of coffee plantation) in October 2010; b. in October 2014. The period between late September and late November is recognized as a dry-wet transitional interval. Photos: a. Gilberto Terra; b. Geovane S. Siqueira. 


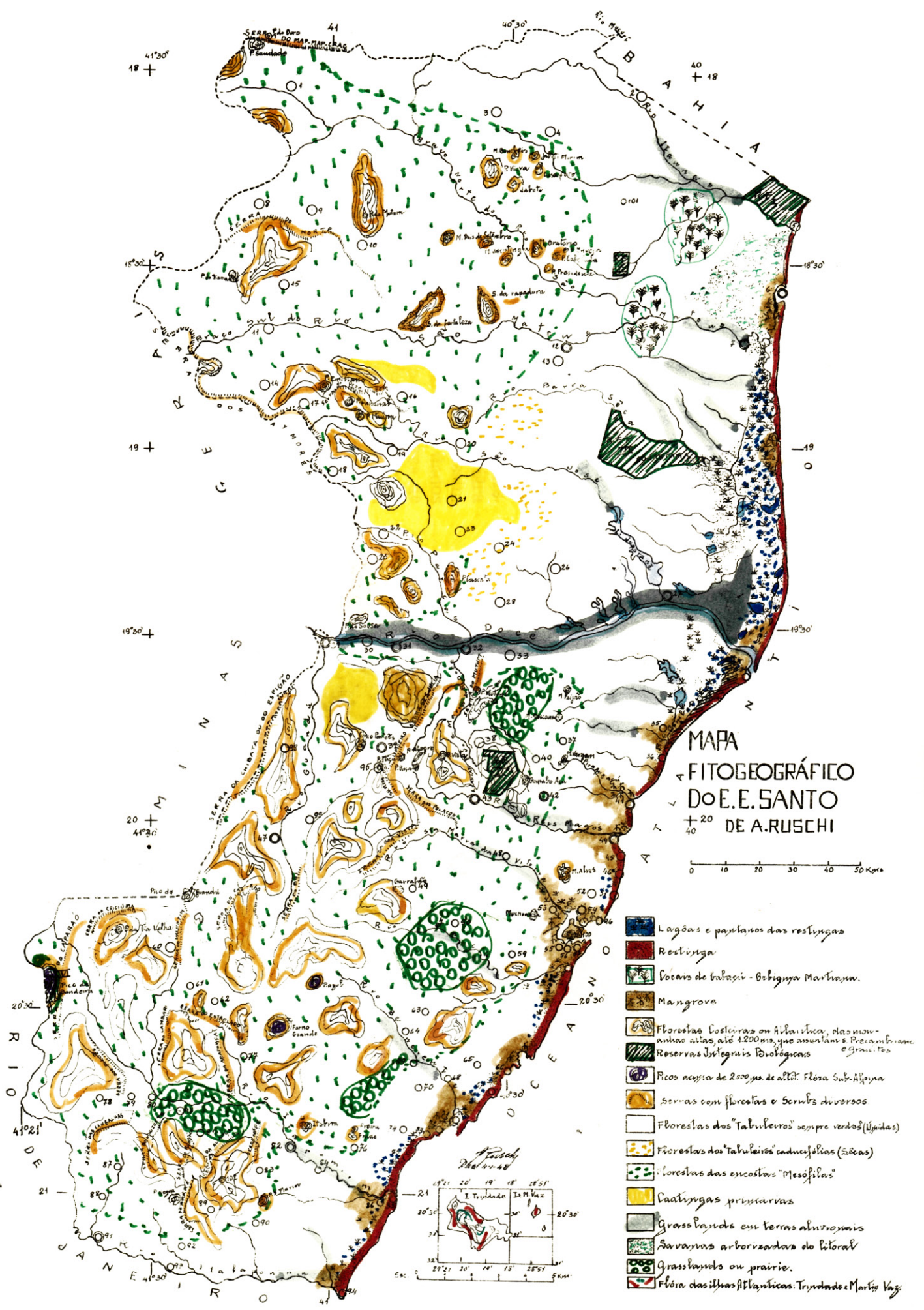

Figura 5 - Mapa fitogeográfico do estado do Espírito Santo segundo Ruschi (1950). Reprodução impressa e eletrônica autorizada pelo Arquivo do Instituto Nacional da Mata Atlântica.

Figure 5 - Phytogeographic map of the state of Espírito Santo according to Ruschi (1950). Graphic and electronic reproduction authorized by the Arquivo do Instituto Nacional da Mata Atlântica. 
uma área mais próxima da costa, na qual é possível reconhecer junto ao paralelo $19^{\circ} \mathrm{S}$ o bloco florestal correspondente ao "Parque de Refúgio e Criação de Animais Silvestres Sooretama”, atual Reserva Biológica de Sooretama.

Um ano mais tarde, Egler (1951) relatou a ocorrência de florestas semidecíduas ao norte do rio Doce por meio de um estudo sócio-ambiental sobre o avanço da colonização de terras durante a primeira metade do século XX. Nas palavras do autor "... Um fato, porém, parece que passou despercebido à maioria dos antigos viajantes: o caráter semidecíduo de uma grande parte da vegetação do rio Doce [...] O que não resta dúvida é que acima do paralelo de $20^{\circ}$ ocorrem, como partes integrantes da chamada "mata costeira" [aspas do autor] ou "mata atlântica" [aspas do autor], extensas e contínuas áreas de matas de caráter indiscutivelmente semidecíduo e que não foram ainda devidamente assinaladas, delimitadas e estudadas".

Na década seguinte, Azevedo (1962) caracterizou os tipos de vegetação do Espírito Santo, denominando de "floresta mesófila de tabuleiros" a vegetação sobre sedimentos da Formação Barreiras ao norte do Rio Doce. Rizzini (1963) denominou de "floresta pluvial dos tabuleiros terciários" as florestas sobre terrenos arenosos do Terciário no norte do Espírito Santo e sul da Bahia, ressaltando as afinidades estruturais e florísticas destas com a Floresta Amazônica (Hileia). Heinsdijk et al. (1965) sugeriu classificar a Floresta de Linhares como "floresta pluvial", mas assumiu que "... Algumas vêzes essa formação poderá ser uma floresta sasonal sempre verde [grafia original do autor]'. Ruschi (1969) revisou o mapa fitogeográfico do Espírito Santo proposto por Ruschi (1950), confirmando em um segundo mapa (ver reprodução na Fig. 6) a existência de florestas de tabuleiro sempre-verdes e ampliando a distribuição das florestas de tabuleiro caducifólias para parte da bacia do rio São Mateus.

Em seguida, Gouvêa (1974) criticou a opinião de Heinsdijk et al. (1965) e considerou que “... a possibilidade da existência de áreas em que a floresta apresenta características de uma "Floresta sazonal" [aspas do autor] dentro dos limites da área inventariada [...] não é hipótese plausível". Segundo Gouvêa (1974), o caráter tropical pluvial da vegetação florestal dos tabuleiros do Espírito Santo seria indiscutível e períodos sub-secos de 1 a 3 meses não seriam suficientes para a caracterização de uma floresta estacional.
Em decorrência do levantamento de reconhecimento dos solos do estado do Espírito Santo, Panoso et al. (1978) denominou a florestas da chamada zona de Tabuleiros como "floresta subperenifólia". Segundo os autores, tal tipologia seria caracterizada por “... uma floresta predominantemente sempre-verde e, [sic] somente decídua em parte. Muitas das espécies sempre-verde [sic] compõem o estrato superior, apresentando, entretanto, propensão a perder suas folhas em estação seca anormal; são espécies "facultativamente decíduas" [aspas do autor], formações mesófilas." No entanto, em um tratado fitogeográfico do Brasil elaborado por Rizzini (1979) o termo "floresta pluvial" reapareceu vinculado ao conjunto de florestas de tabuleiros do norte do Espírito Santo. Em sequência, Amorim (1984) citou as florestas de tabuleiro do norte do Espírito Santo apenas como "uma vegetação densa" no volume do Inventário Florestal Nacional que tratou das florestas nativas dos estados do Rio de Janeiro e Espírito Santo.

Alguns anos depois, o estudo fitogeográfico da Folha SE.24 Rio Doce elaborada pelo Projeto RADAMBRASIL (Jordy Filho 1987) utilizou os critérios de classificação de Veloso \& Góes-Filho (1982) para ligar as florestas de tabuleiro do norte do Espírito Santo à tipologia "floresta ombrófila densa", embora características de espécies do dossel da floresta ao sul do paralelo 18³0'S (onde está localizada a Floresta de Linhares) tenham lançado dúvidas sobre o seu regime climático. Segundo o autor, quando comparadas com a floresta ao norte do paralelo $18^{\circ} 30^{\prime} \mathrm{S}$ “... esta floresta destaca-se pelas diferenças estruturais que algumas espécies do estrato dominante apresentam, como brotos protegidos, folhas coriáceas e troncos de casca grossa, o que cause justa preocupação quanto à sua classificação, se ombrófila ou estacional." Na verdade, é preciso ressaltar que, a despeito das dúvidas existentes à época, a classificação da floresta como ombrófila densa foi deduzida a partir de uma análise da distribuição geográfica de gêneros ocorrentes na flora arbórea da Reserva Florestal da Companhia Vale do Rio Doce (atual Reserva Natural Vale), a qual indicou fortes relações filogenéticas desta floresta com as florestas pluviais do sul da Bahia e da Amazônia. Entretanto, análises paleoclimáticas e fitogeográficas recentes sugerem que tal condição não necessariamente indicaria a ocorrência moderna de uma floresta pluvial ou ombrófila na região de Linhares, uma vez que supostamente a 


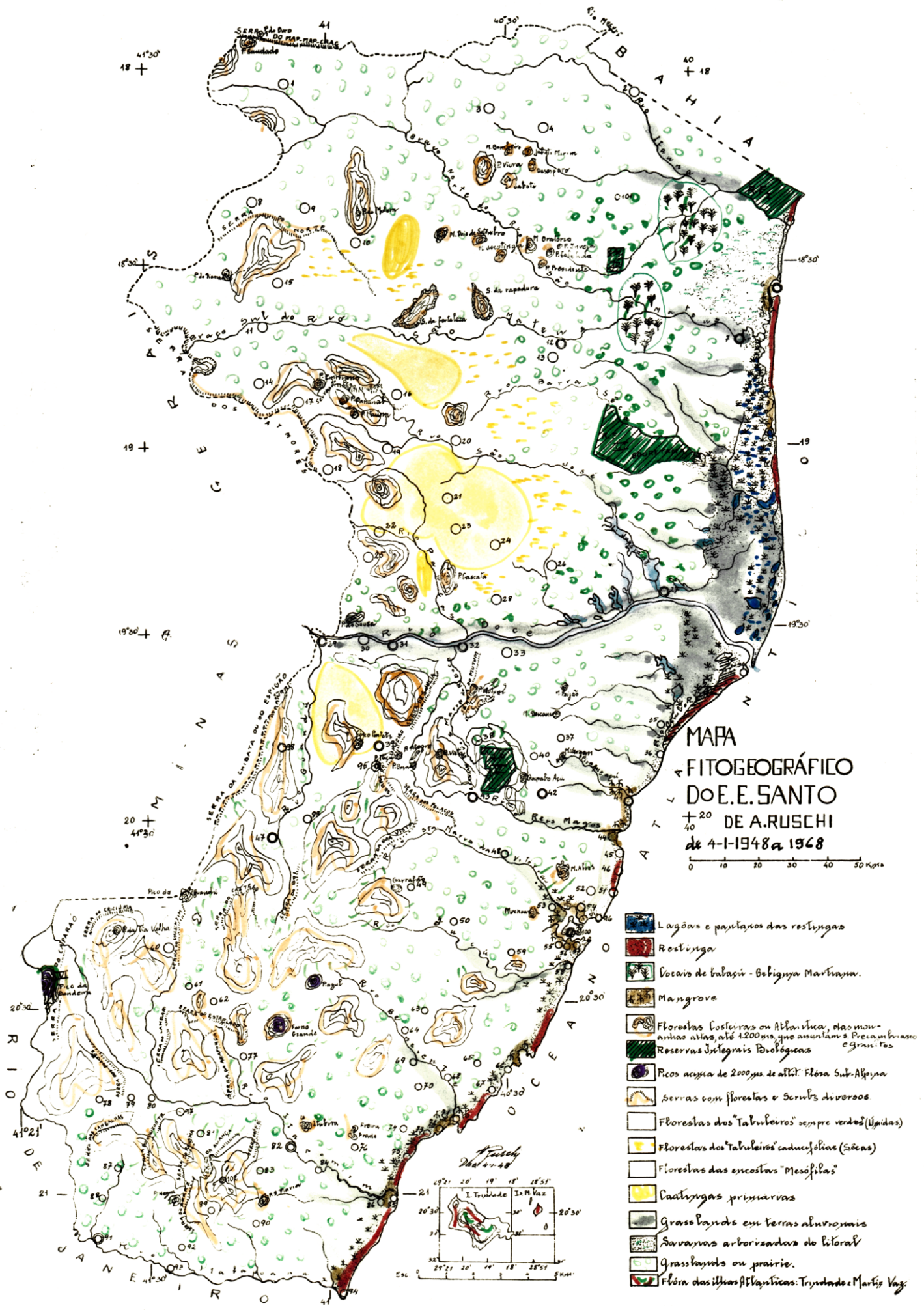

Figura 6 - Mapa fitogeográfico do estado do Espírito Santo segundo Ruschi (1969). Reprodução impressa e eletrônica autorizada pelo Arquivo do Instituto Nacional da Mata Atlântica.

Figure 6 - Phytogeographic map of the state of Espírito Santo according to Ruschi (1969). Graphic and electronic reproduction authorized by the Arquivo do Instituto Nacional da Mata Atlântica. 
presença de gêneros típicos de climas pluviais seria uma herança do período com clima mais úmido e menos sazonal ocorrido há cerca de 7.000-4.000 anos, durante o Holoceno Médio (Buso Junior. et al. 2013; Saiter et al. 2016a; Saiter et al. 2016b).

Em um trabalho contemporâneo ao de Jordy Filho (1987), Jesus (1987) descreveu aspectos ecológicos da Floresta de Linhares, dentre eles um período muito curto de semideciduidade ocorrendo na estação seca. Pouco tempo depois, Peixoto \& Gentry (1990) descreveram a diversidade e composição de um trecho da Floresta de Linhares, trazendo à tona o termo "floresta ombrófila semidecídua" (mais tarde esse termo seria recordado por Kindel et al. 1999; e Kindel \& Garay 2001). Tal denominação, entretanto, mistura conceitos flagrantemente opostos segundo os sistemas de classificação da vegetação brasileira que eram usados naquela época (principalmente os de Veloso \& Góes-Filho 1982; e Veloso et al., 1991). Nesses sistemas, as florestas ombrófilas são caracterizadas por elevada precipitação, que é bem distribuída ao longo do ano, e por ausência de período biologicamente seco. Por outro lado, as florestas estacionais semideciduais são marcadas por uma distribuição sazonal de chuvas, com ocorrência de uma estação seca pronunciada.

Ainda que até o início da década de 1990 alguns estudos já tivessem indicado o possível caráter estacional e semidecíduo da Floresta de Linhares, os resultados do Projeto RADAMBRASIL (Jordy Filho 1987) levaram à publicação de duas edições do Mapa de Vegetação do Brasil (IBGE 1988, 1993) mostrando a região como parte integrante da tipologia de floresta ombrófila densa. Devido à influência desses mapas sobre a organização de iniciativas oficiais de conservação e pesquisa da biodiversidade, desde então muitos estudos ecológicos têm optado por retratar a Floresta de Linhares como uma "floresta ombrófila densa" ou dense rain forest (por exemplo, Oliveira-Filho \& Fontes 2000; Oliveira-Filho et al. 2005; Paula et al. 2009; Paula \& Soares 2011; Magnago et al. 2014). Todavia, na contramão dessa tendência, alguns estudos têm considerado observações de campo ou análises do clima local para adotar o termo "floresta estacional semidecidual" (por exemplo, Rolim \& Nascimento 1997; Rolim et al. 1999; Kindel \& Garay 2002; Saiter et al. 2015), uma denominação disponível no sistema de Veloso et al. (1991).

Nesse contexto, Engel (2001) realizou um estudo fenológico que revelou os efeitos da distribuição sazonal de chuvas sobre a Floresta de Linhares. Tal estudo monitorou por 11 anos (1982-1992) a fenologia de 41 espécies de dossel (205 árvores no total, sendo cinco de cada espécie) e constatou que 43,9\% delas são brevidecíduas (desfolhadas por cerca de uma semana, antes do brotamento no início da estação chuvosa) e $12,2 \%$ são decíduas (perdem as folhas no final da estação seca e permanecem desfolhadas por várias semanas até o brotamento na estação chuvosa). O máximo de queda foliar ocorreu na transição da estação seca para a chuvosa, quando, em média, 30\% das espécies e 15\% dos indivíduos monitorados mostraram queda total ou quase total de folhas. Baseando-se nessas informações, a autora classificou a Floresta de Linhares como "floresta estacional perenifólia" seguindo critérios de Longman \& Jeník (1987), e indicou que essa seria uma tipologia transicional entre os conceitos de "floresta ombrófila densa" e "floresta estacional semidecidual" propostos por Veloso et al. (1991). Para Longman \& Jeník (1987), o dossel de uma floresta tropical estacional perenifólia é dominado por espécies sempre-verdes, das quais um máximo de $30 \%$ apresentam desfolha durante a época seca do ano.

Os dados de Engel (2001), entretanto, indicam que em anos com secas mais severas, como no período de 1987 a 1990, a proporção de indivíduos totalmente desfolhados (20-30\%) foi duas a três vezes maior do que aquela registrada em anos com secas amenas, como em 1982 e 1985. Aqui devemos ressaltar que o Instituto Nacional de Pesquisas Espaciais (CPTEC-INPE; < http:// enos.cptec.inpe.br/>) considera a ocorrência de ENOS em níveis moderados a fortes entre 1987 e 1990. Dessa forma, embora Engel (2001) não tenha abordado a relação da deciduidade da Floresta de Linhares com os efeitos climáticos de ENOS, é provável que as precipitações anuais de apenas 800-1000 $\mathrm{mm}$ registradas nesse período (ver dados em Kierulff et al. 2015) tenham levado à maior deciduidade do componente arbóreo.

Posteriormente, Vicens et al. (2004) sugeriu o caráter semicaducifólio da Floresta de Linhares após constatar a redução em cerca de $25 \%$ do valor de um índice de vegetação (NDVI - Normalized Difference Vegetation Index) entre o início e o final da estação seca do ano de 1997, respectivamente maio (NDVI médio $=0,60)$ e setembro (NDVI médio $=0,46)$. Os índices de vegetação são produzidos a partir de imagens multitemporais de sensoriamento remoto e se prestam ao monitoramento de alterações no vigor da cobertura 
vegetal (Almeida et al. 2008). Devemos ainda informar que o biênio 1997-1998 também foi considerado pelo Instituto Nacional de Pesquisas Espaciais (CPTEC-INPE; <http://enos.cptec. inpe.br/>) como um período com fortes efeitos climáticos de El-Niño. Assim como especulado a partir dos dados de Engel (2001), alterações nos padrões térmicos e de umidade podem ter sido responsáveis pela condição semidecídua encontrada por Vicens et al. (2004). Corroboram essa afirmação os efeitos de eventos do El-Niño sobre a dinâmica da Floresta de Linhares (aumento das taxas de mortalidade de árvores e declínio de biomassa) que foram registrados por Rolim et al. (1999) e Rolim et al. (2005).

Diante das evidências de semideciduidade na Floresta de Linhares, Rizzini \& Garay (2004) analisaram parâmetros físicos e químicos das folhas de 73 espécies arbóreas que apresentaram as maiores taxas de cobertura em quatro tipos florestais existentes na Reserva Natural Vale (mata alta, mata ciliar, capoeira após extração seletiva de madeira e capoeira após queimada) e constataram que certas espécies conseguem se manter perenifólias (ou sempre-verdes) porque adotam a esclerofilia como mecanismo adaptativo frente ao estresse hídrico. Tais espécies apresentam índice de esclerofilia (IEp) $\geq 0,52 \mathrm{~g} / \mathrm{dm}^{2}$. Por outro lado, espécies com grau intermediário de esclerofilia $\left(0,52 \geq \operatorname{IEp} \geq 0,33 \mathrm{~g} / \mathrm{dm}^{2}\right)$, notadamente as mais abundantes nos trechos de floresta analisados, são semicaducifólias e podem controlar a proporção de queda de folhas segundo a severidade da seca. Espécies não-esclerófilas (ou de folhas leves; IEp $\leq 0,33 \mathrm{~g} / \mathrm{dm}^{2}$ ) são caducifólias e ocorrem em menor densidade que as espécies perenifólias e semicaducifólias.

Tais constatações reafirmam as informações de Jordy Filho (1987) sobre a ocorrência de atributos estruturais típicos de resistência à seca em algumas espécies arbóreas dominantes na Floresta de Linhares, e de Panoso et al. (1978) sobre a existência de muitas espécies sempre-verdes facultativamente decíduas (propensas a perder a folhagem em estações secas anormais). Esse último caso constitui evidência de que a floresta poderia responder de forma diferenciada à variação interanual de precipitação e severidade da seca. Embasamento adicional para tal conclusão pode ser encontrado no estudo de Almeida et al. (2008) realizado na Reserva Biológica de Sooretama, o qual revelou um dinamismo sazonal dos valores de outro índice de vegetação (EVI - Enhanced
Vegetation Index) e uma forte correlação destes com dados de precipitação. Segundo os autores, a série temporal do índice de vegetação (abril de 2000 a outubro de 2005) indicou que as respostas fenológicas do dossel florestal, como o desenvolvimento, a descoloração e a senescência de folhas, variaram de ano para ano acompanhando as condições climáticas.

Recentemente, Rolim et al. (2016) apresentaram uma análise de balanço hídrico normal (dados da série histórica 1975-2004) que indicou a ocorrência de oito meses (fevereiro-outubro) com deficit hídrico na Floresta de Linhares, mas totalizando apenas $41,4 \mathrm{~mm}$ de deficit. Os autores também utilizaram o índice de perumidade de Walsh (1996) para confirmar a estacionalidade climática e se apoiaram nos dados de Engel (2001) para concluir que, em média, as árvores da Floresta de Linhares apresentam grau de deciduidade maior do que aquele de uma floresta ombrófila, mas menor do que o normalmente encontrado em uma floresta estacional semidecidual. Tais argumentos levaram os autores a sugerir o uso da denominação "floresta estacional perenifólia" para a Floresta de Linhares.

\section{Uma nova e flexível classificação}

Como as contradições entre os estudos anteriormente citados trazem grande insegurança, alguns autores têm preferido alertar sobre o uso controverso de diferentes denominações no caso da Floresta de Linhares (por exemplo, Rizzini et al. 1997; Engel \& Martins 2005; Garay et al. 2008; Peixoto et al. 2008; Kierulff et al. 2015). De fato, essa controvérsia pode ser encarada como o resultado de pareceres construídos a partir de diferentes métodos e escalas espaciais e temporais, retratando o pensamento dos autores e o estado do conhecimento à época em que cada um foi elaborado.

Há também de se compreender a dura tarefa de classificar a vegetação tendo como base parâmetros que flutuam ao sabor de um ambiente naturalmente dinâmico. Nesse sentido, seria razoável supor que a observação da Floresta de Linhares em anos mais úmidos, quando a fisionomia semidecídua certamente não foi evidente, encorajou alguns autores a denominá-la de "floresta ombrófila densa", "floresta pluvial", "floresta sempreverde" ou "floresta perenifólia". Por outro lado, a observação da floresta em anos mais secos deve ter induzido a adoção dos termos "floresta mesófila", "floresta estacional semidecidual" ou "floresta subperenifólia". 
Devemos ainda assumir o caráter muitas vezes arbitrário das classificações de vegetação. Nesse sentido, o uso da denominação "floresta estacional perenifólia", como sugerido por Engel (2001) e Rolim et al. (2016), pode estar correto de acordo com critérios de Longman \& Jeník (1987), mas não encontra suporte na classificação de Veloso et al. (1991), devido à falta de flexibilidade desse último sistema para a construção do termo "floresta estacional densa" (se é que esse poderia ser mesmo um sinônimo dos termos "floresta estacional perenifólia" ou "floresta estacional sempreverde"). Tomando ainda por base a classificação das fitofisionomias da América do Sul cisandina tropical e subtropical proposta por Oliveira-Filho (2009), o termo "floresta estacional perenifólia" seria possível, mas não descreveria a real condição da Floresta de Linhares. Segundo o autor, florestas estacionais perenifólias são atribuídas a fundos de vales úmidos onde a estação seca é compensada por reservas de água no solo.

Curiosamente, a recente revisão do Manual Técnico da Vegetação Brasileira (IBGE 2012), um produto derivado da classificação de Veloso et al. (1991), incluiu o termo "floresta estacional sempre-verde" (ou "floresta estacional perenifólia") dentre suas tipologias de vegetação com o claro objetivo de contemplar as florestas sempre-verdes ocorrendo sob clima sazonalmente seco na borda sul da Amazônia, em Mato Grosso (região do Alto Xingu). Segundo IBGE (2012), nessa região as florestas estacionais perenifólias típicas ocorrem sobre latossolos profundos fora dos vales úmidos, os quais, por sua vez, são ocupados por uma "fisionomia ombrófila" (termo que consideramos inadequado, pois sugere um regime climático pluvial não encontrado na região) floristicamente distinta. Houve, entretanto, um cuidado de IBGE (2012) em informar que a perenidade das florestas da borda sul da Amazônia foi confirmada pela análise de um índice de vegetação (NDVI) no período 1982-1999 (esse mesmo índice foi utilizado por Vicens et al. 2004, para confirmar a semideciduidade da Floresta de Linhares no ano de 1997). Segundo Ivanauskas et al. (2008) tal perenidade seria resultado da presença de inúmeros cursos de água em relevo plano, bem como da suposta capacidade atribuída às raízes de árvores amazônicas de absorver água em profundidades maiores que $8 \mathrm{~m}$ durante a estação seca (Nepstad et al. 1994).

Essa última justificativa também foi especulada para o caso da Floresta de Linhares (Rolim et al. 2016). Entretanto, faltam estudos locais que indiquem a profundidade média atingida pelas raízes das árvores e que confirmem se tal profundidade seria suficiente para atingir camadas de solo mais ricas em água. É provável que algumas espécies não possuam raízes tão longas, ou que os estoques de água no solo não sejam suficientes para atendimento das demandas hídricas da vegetação durante períodos muito secos, haja vista os efeitos de episódios ENOS sobre a mortalidade de árvores e os índices de vegetação já relatados acima (Almeida et al. 2008; Vicens et al. 2004; Rolim et al. 1999; Rolim et al. 2005). De qualquer forma, podemos acrescentar que os argissolos da Floresta de Linhares possuem maior capacidade de drenagem que os latossolos da borda sul da Amazônia. Além disso, as médias de precipitação anual na borda sul da Amazônia normalmente alcançam níveis superiores a $1500 \mathrm{~mm}$ (Ivanauskas et al. 2008), contra cerca de $1200 \mathrm{~mm}$ na Floresta de Linhares (como já informamos, anos menos chuvosos são relativamente comuns).

Diante dessas informações, não podemos afirmar que a Floresta de Linhares seria sempre uma "floresta estacional perenifólia" segundo a classificação de IBGE (2012). Também não há segurança para apoiar definitivamente o uso das denominações "floresta estacional semidecidual" (sensu Veloso et al. 1991; e IBGE 2012) e "floresta estacional semideciduifólia" (sensu Oliveira-Filho 2009), pois é notável a ocorrência de anos mais úmidos em que estações secas amenas (Fig. 3) levaram à fisionomia sempre-verde ou perenifólia. A única certeza é de que o regime climático estacional da Floresta de Linhares não permite a sua classificação como floresta ombrófila.

Há, portanto, a necessidade de se considerar a flexibilidade do regime de renovação foliar da Floresta de Linhares em sua própria classificação. Em vez da adoção de uma classificação rígida, imutável, entendemos que seria mais natural denominá-la duplamente, como floresta estacional semidecidual nos períodos anuais ou supra-anuais marcados por déficit hídricos pronunciados, e como floresta estacional perenifólia nos períodos anuais ou supra-anuais sem déficit hídrico significativo. Evidentemente, essa alternância de denominações poderá causar certa desconfiança em fitogeógrafos acostumados a classificações tradicionais onde as tipologias da vegetação foram pensadas como entidades independentes. Então, se for essencial eleger um único termo para descrever a Floresta de Linhares, sugerimos que seja "floresta estacional semidecidual a perenifólia”. 
Esperamos que nossa proposta estimule futuras discussões sobre a flexibilização dos sistemas de classificação da vegetação brasileira, abrindo espaço para análises que considerem realidades ambientais inconstantes. Nossas interpretações claramente demonstraram que, para o caso da Floresta de Linhares, dados mensais médios de precipitação não exprimem a realidade dos períodos biologicamente secos ano a ano, e mascararam a amplitude das variações interanuais do clima, fatores que consideramos imprescindíveis para a classificação de florestas. É possível que situações semelhantes ocorram em outras regiões do Domínio Atlântico brasileiro, uma vez que a própria "linha imaginária" que divide as florestas ombrófilas e as florestas estacionais semideciduais (segundo o Mapa de Vegetação do Brasil; IBGE 2004) seria uma arbitrariedade necessária dentro de um sistema de classificação que considera apenas parcialmente as implicações da dinâmica temporal do clima sobre a fisionomia da vegetação. Nesse caso, não seria estranho supor a flutuação dessa "linha" ano a ano, ora avançando para a costa durante estações secas mais severas, ora retraindo para o interior em estações secas mais amenas. Essa suposição é corroborada por estudos de fitogeografia ecológica (por exemplo, Oliveira-Filho \& Fontes 2000; Oliveira-Filho et al. 2005; Saiter et al. 2015; Saiter et al. 2016b) que já reconheceram gradientes florísticos contínuos entre florestas interioranas e costeiras do Domínio Atlântico brasileiro.

Por fim, recomendamos que as bases de dados utilizadas para a confecção das diversas versões já publicadas do Mapa de Vegetação do Brasil (IBGE 1988, 1993, 2004) sejam incrementadas com novas informações, incluindo séries climáticas mais longas, análises de balanço hídrico sequencial e monitoramentos de índice de vegetação. Isso permitirá não só a construção de um mapa mais moderno para o Domínio Atlântico brasileiro, mas também trará um pouco mais de luz sobre sua condição ambientalmente dinâmica e complexa.

\section{Agradecimentos}

A Gilberto Terra e a Geovane S. Siqueira, a concessão de fotografias representativas da fisionomia da Floresta de Linhares; e ao Instituto Nacional da Mata Atlântica, a autorização para reprodução de imagens da obra do naturalista Augusto Ruschi. F.Z.S. agradece à Coordenação de Aperfeiçoamento de Pessoal de Nível Superior (CAPES-7748/13-2), a bolsa de Doutorado Sanduíche. A.T.O.F. agradece ao
Conselho Nacional de Desenvolvimento Científico e Tecnológico, a bolsa de Produtividade em Pesquisa (CNPq; 303458/2010-0).

\section{Referências}

Almeida AQ, Silva GF, Pezzopane JEM \& Ribeiro CAD (2008) Enhanced Vegetation Index (EVI) na análise da dinâmica da vegetação da Reserva Biológica de Sooretama, ES. Revista Árvore 32: 1099-1107.

Amorim HB (1984) Inventário das florestas nativas dos estados do Rio de Janeiro e Espírito Santo. Instituto Brasileiro de Desenvolvimento Florestal, Brasília. 204p.

Azevedo LG (1962) Tipos de vegetação do estado do Espírito Santo. Revista Brasileira de Geografia 24: 111-115.

Box EO \& Fujiwara K (2013) Vegetation types and their broad-scale distribution. In: van der Maarel E \& Franklin J (eds.) Vegetation ecology. $2^{\text {nd }}$ ed. Wiley-Blackwell, Chichester. Pp. 455-485.

Buso Junior AA, Pessenda LCR, Oliveira PE, Giannini PCF, Cohen MCL, Volkmer-Ribeiro C, Oliveira SMB, Rossetti DF, Lorente FL, Borotti Filho MA, Schiavo JA, Bendassolli JA, Franca MC, Guimarães JTF \& Siqueira GS (2013) Late Pleistocene and Holocene vegetation, climate dynamics, and Amazonian taxa in the Atlantic Forest, Linhares, SE Brazil. Radiocarbon 55: 1747-1762.

Cupolillo F, Abreu ML \& Vianello RL (2008) Climatologia da bacia do Rio Doce e sua relação com a topografia local. Geografias 4: 45-60.

Egler WA (1951) A zona pioneira ao norte do Rio Doce. Revista Brasileira de Geografia 2: 223-264.

Engel VL (2001) Estudo fenológico de espécies arbóreas de uma floresta tropical em Linhares, ES. Tese de Doutorado. Universidade Estadual de Campinas, Campinas. 137p.

Engel VL \& Martins FR (2005) Reproductive phenology of Atlantic forest tree species in Brazil: an eleven year study. Tropical Ecology 46: 1-16.

Garay I, Noronha F \& Moraes VR de (2008) Raízes finas nos horizontes do topo do solo em relação a atividades extrativistas em fragmentos de Floresta Atlântica de Tabuleiros, em Sooretama, ES. Floresta e Ambiente 15: 34-48.

Gouvêa JBS (1974) Considerações e reconhecimento fitogeográfico em áreas do baixo curso do vale do rio Doce (Espírito Santo). Boletim Paulista de Geografia 49: 23-30.

Heinsdijk D, Macêdo JG, Andel S \& Ascoly RB (1965) A floresta do norte do Espírito Santo: dados e conclusões dum inventário florestal pilôto. Boletim $\mathrm{n}^{\circ} 7$. Setor de Inventários Florestais, Ministério da Agricultura, Rio de Janeiro. 69p.

IBGE (1988) Mapa de vegetação do Brasil. Fundação Instituto Brasileiro de Geografia e Estatística, Rio de Janeiro. 
IBGE (1993) Mapa de vegetação do Brasil. 2a ed. Fundação Instituto Brasileiro de Geografia e Estatística, Rio de Janeiro.

IBGE (2004) Mapa de vegetação do Brasil. $3^{\mathrm{a}}$ ed. Instituto Brasileiro de Geografia e Estatística, Rio de Janeiro. Disponível em <ftp://ftp.ibge.gov.br/ Cartas e Mapas/Mapas Murais/>. Acesso em 3 março 2017 .

IBGE (2012) Manual técnico da vegetação brasileira. Série Manuais Técnicos em Geociências 1. 2 $2^{\mathrm{a}}$ ed. Instituto Brasileiro de Geografia e Estatística, Rio de Janeiro. 275p.

Ivanauskas NM, Monteiro R \& Rodrigues RR (2008) Classificação fitogeográfica das florestas do Alto Rio Xingu. Acta Amazonica 38: 387-402.

Jesus RM (1987) Mata Atlântica de Linhares: aspectos florestais - a experiência da CVRD. In: Ministério do Desenvolvimento Urbano e do Meio Ambiente (org.) Anais do seminário sobre desenvolvimento econômico e impacto ambiental em áreas de trópico úmido brasileiro. CVRD, Rio de Janeiro. Pp. 35-71.

Jordy Filho A (1987) Vegetação: as regiões fitoecológicas, sua natureza e seus recursos econômicos. Estudo fitogeográfico. In: IBGE (org.) Folha SE. 24 Rio Doce: geologia, geomorfologia, pedologia, vegetação, uso potencial da terra. Fundação Instituto Brasileiro de Geografia e Estatística, Rio de Janeiro. Pp. 353-385.

Kierulff MCM, Avelar LHS, Ferreira MES, Povoa KF \& Bérnils RS (2015) Reserva Natural Vale: história e aspectos físicos. Ciência \& Ambiente 49: 7-40.

Kindel A, Barbosa PMS, Pérez DVI \& Garay I (1999) Efeito do extrativismo seletivo de espécies arbóreas da floresta atlântica de tabuleiros na matéria orgânica e outros atributos do solo. Revista Brasileira de Ciência do Solo 23: 465-474.

Kindel A \& Garay I (2001) Caracterização de ecossistemas da Mata Atlântica de Tabuleiros por meio das formas de húmus. Revista Brasileira de Ciência do Solo 25: 551-563.

Kindel A \& Garay I (2002) Humus form in ecosystems of the Atlantic Forest, Brazil. Geoderma 108: 101-118.

Köppen W (1948) Climatologia: con un estudio de los climas de la tierra. Fondo de Cultura Economica, Mexico, D.F. 479p.

Longman KA \& Jeník J (1987) Tree growth physiology. In: Longman KA \& Jeník J (eds.) Tropical forests and its environment. $2^{\text {nd }}$ ed. Longman, New York. Pp. 124-201.

Magnago LF, Edwards DP, Edwards FA, Magrach A, Martins SV \& Laurance WF (2014) Functional attributes change but functional richness is unchanged after fragmentation of Brazilian Atlantic forests. Journal of Ecology 102: 475-485.

Mucina L (1997) Classification of vegetation: past, present and future. Journal of Vegetation Science 8: 751-760.
Nepstad DC, Carvalho CR, Davidson EA, Jipp PH, Lefebvre VA, Negreiros GH, Silva ED, Stone TA, Trumbore SE \& Vieira S (1994) The role of deep roots in the hydrological and carbon cycles of Amazonian forests and pastures. Nature 372: 666-669.

Oliveira-Filho AT (2009) Classificação das fitofisionomias da América do Sul Cisandina Tropical e Subtropical: proposta de um novo sistema - prático e flexível ou uma injeção a mais de caos? Rodriguésia 60 : 237-258.

Oliveira-Filho AT \& Fontes MAL (2000) Patterns of floristic differentiation among Atlantic forests in southeastern Brazil and the influence of climate. Biotropica 32: 793-810.

Oliveira-Filho AT, Tameirão-Neto E, Carvalho WAC, Werneck M, Brina AE, Vidal CV, Rezende SC \& Pereira JAA (2005) Análise florística do compartimento arbóreo de áreas de Floresta Atlântica sensu lato na região das bacias do leste (Bahia, Minas Gerais, Espírito Santo e Rio de Janeiro). Rodriguésia 56: 185-235.

Panoso LA, Gomes IA, Pires Filho AM \& Bonelli S (1978) Levantamento de reconhecimento dos solos do estado do Espírito Santo. Boletim Técnico $\mathrm{n}^{\circ}$ 45. Empresa Brasileira de Pesquisa Agropecuária, Serviço Nacional de Levantamento e Conservação de Solos, Rio de Janeiro. 461p.

Paula A de, Lopes WP \& Silva AF (2009) Florística e estrutura de fragmentos florestais no entorno da Lagoa Juparanã, Linhares, Espírito Santo, Brasil. Boletim do Museu de Biologia Mello Leitão (nova série) 26: 5-23.

Paula A de \& Soares JJ (2011) Estrutura horizontal de um trecho de floresta ombrófila densa das terras baixas na Reserva Biológica de Sooretama, Linhares, ES. Floresta 41: 321-334.

Peet RK \& Roberts DW (2013) Classification of natural and semi-natural vegetation. In: van der Maarel E \& Franklin J (eds.) Vegetation ecology. $2^{\text {nd }}$ ed. WileyBlackwell, Chichester. Pp. 28-70.

Peixoto AL \& Gentry A(1990) Diversidade e composição florística da mata de tabuleiro na Reserva Florestal de Linhares (Espírito Santo, Brasil). Revista Brasileira de Botânica 13: 19-25.

Peixoto AL \& Jesus RM (2016) Reserva Natural Vale: memórias de 65 anos de conservação. In: Rolim SG, Menezes LFT \& Srbek-Araujo AC (eds.) Floresta Atlântica de Tabuleiro: diversidade e endemismos na Reserva Natural Vale. Ed. Rupestre, Belo Horizonte. Pp. 21-29.

Peixoto AL, Silva IM, Pereira OJ, Simonelli M, Jesus RM \& Rolim SG (2008) Tabuleiro Forests North of the Rio Doce: their representation in the Vale do Rio Doce Natural Reserve, Espírito Santo, Brazil. In: Thomas WW (ed.) The Atlantic Coastal Forest of Northeastern Brazil. The New York Botanical Garden Press, New York. Memoirs of The New York Botanical Garden 100: 319-350. 
Rizzini CT (1963) Nota prévia sobre a divisão fitogeográfica (florístico-sociológica) do Brasil. Revista Brasileira de Geografia 1: 3-64.

Rizzini CT (1979) Tratado de fitogeografia do Brasil: aspectos sociológicos e florísticos. Vol. 2. Edusp, São Paulo. 374p.

Rizzini CM, Aduan RE, Jesus R \& Garay I (1997) Floresta pluvial de tabuleiro, Linhares, ES, Brasil: sistemas primários e secundários. Leandra 12: 54-76.

Rizzini CM \& Garay I (2004) A esclerofilia foliar como indicador funcional do status da biodiversidade em Floresta Atlântica de Tabuleiros. In: Garay I \& Rizzini CM (eds.) A Floresta Atlântica de Tabuleiros: diversidade funcional da cobertura arbórea. 2a ed. Vozes, Petrópolis. Pp. 35-50.

Rolim GS, Sentelhas PC \& Barbieri V (1998) Planilhas no ambiente Excel $^{\mathrm{TM}}$ para os cálculos de balanços hídricos: normal, sequencial, de cultura e de produtividade real e potencial. Revista Brasileira de Agrometeorologia 6: 133-137.

Rolim SG (1999) Mortalidade e recrutamento de árvores na Floresta Atlântica em Linhares (ES). Scientia Forestalis 55: 49-69.

Rolim SG \& Nascimento HEM (1997) Análise da riqueza, diversidade e relação espécie-abundância de uma comunidade arbórea tropical em diferentes intensidades amostrais. Scientia Forestalis 52: 7-16.

Rolim SG, Jesus RM, Nascimento HEM, Couto HTZ \& Chambers JQ (2005) Biomass change in an Atlantic tropical moist forest: the ENSO effect in permanent sample plots over a 22-year period. Oecologia 142: 238-246.

Rolim SG, Ivanauskas NM \& Engel VL (2016) As florestas de tabuleiro do norte do Espírito Santo são ombrófilas ou estacionais? In: Rolim SG, Menezes LFT \& Srbek-Araujo AC (eds.) Floresta Atlântica de Tabuleiro: diversidade e endemismos na Reserva Natural Vale. Ed. Rupestre, Belo Horizonte. Pp. 47-60.

Ruschi A (1950) Fitogeografia do estado de Esp. Santo: considerações gerais sobre a distribuição da flora no estado do E. Santo. Boletim do Museu de Biologia Prof. Mello Leitão (Série Botânica) 1: 1-353.

Ruschi A (1969) O mapa fitogeográfico atual do estado do E. Santo. Boletim do Museu de Biologia Prof. Mello-Leitão (Série Proteção à Natureza) 30: 1-50.

Saiter FZ, Rolim SG \& Oliveira-Filho AT (2016a) A floresta de Linhares no contexto fitogeográfico do leste do Brasil. In: Rolim SG, Menezes LFT \& SrbekAraujo AC (eds.) Floresta Atlântica de Tabuleiro: diversidade e endemismos na Reserva Natural Vale. Ed. Rupestre, Belo Horizonte. Pp. 61-69.

Saiter FZ, Brown JL, Thomas WW, Oliveira-Filho AT \& Carnaval AC (2016b). Environmental correlates of floristic regions and plant turnover in the Atlantic Forest hotspot. Journal of Biogeography 43: 23222331.

Saiter FZ, Eisenlohr PV, França GS, Stehmann JR, Thomas WW \& Oliveira-Filho AT (2015) Floristic units and their predictors unveiled in part of the Atlantic Forest hotspot: implications for conservation planning. Anais da Academia Brasileira de Ciências 87: 2031-2046.

Santos RD, Barreto WO, Silva EF, Araújo WS, Claessen MEC, Paula JL, Souza JLR, Pérez DV \& Souza JS (2004) Levantamento expedito dos solos das reservas florestais de Linhares e Sooretama no estado do Espírito Santo. Boletim de Pesquisa e Desenvolvimento 49. Embrapa Solos, Rio de Janeiro. 68p.

Tedeschi RG, Grimm AM \& Cavalcanti IFA (2016) Influence of Central and East ENSO on precipitation and its extreme events in Souh America during austral autumn and winter. International Journal of Climatology 36: 4797-4814.

Thornthwaite CW \& Mather JR (1955) The water balance. Publications in Climatology, vol. VIII, n. 1. Drexel Institute of Technology, Laboratory of Climatology, Centerton. 104p.

Veloso HP \& Góes-Filho L (1982) Fitogeografia brasileira: classificação fisionômico-ecológica da vegetação neotropical. Boletim Técnico Projeto RADAMBRASIL, Série Vegetação, n. 1. Projeto RADAMBRASIL, Salvador. 86p.

Veloso HP, Rangel Filho ALR \& Lima JCA (1991) Classificação da vegetação brasileira, adaptada a um sistema universal. IBGE, Departamento de Recursos Naturais e Estudos Ambientais, Rio de Janeiro. 124p.

Vicens RS, Agarez FV \& Garay I (2004) A região da REBIO Sooretama e da Reserva de Linhares e seu entorno: das características físico-geográficas ao uso da terra. In: Garay I \& Rizzini CM (eds.) A Floresta Atlântica de Tabuleiros: diversidade funcional da cobertura arbórea. $2^{\text {a }}$ ed. Vozes, Petrópolis. Pp. 7-15. 
